\title{
An Influence Study of Parallel Hybrid Vehicle Propulsion System CONFIGURATIONS
}

\author{
Jony Javorski Eckert ${ }^{1}$, Fernanda Cristina Corrêa ${ }^{2}$, Fabio Mazzariol Santiciolli ${ }^{1}$ \\ Eduardo dos Santos Costa $^{1}$, Heron José Dionísio ${ }^{1}$ and Franco Giuseppe Dedini ${ }^{1}$ \\ ${ }^{1}$ State University of Campinas - UNICAMP \\ ${ }^{2}$ Federal Technological University of Paraná - UTFPR, Campus Ponta Grossa \\ E-mails: javorski@fem.unicamp.br, fernandacorrea@utfpr.edu.br, fabio@fem.unicamp.br, \\ eduardo.costa@fem.unicamp.br, heronj.dionisio@gmail.com, dedini@fem.unicamp.br
}

\begin{abstract}
The hybrid electric vehicle (HEV) became an alternative to reduce the fuel consumption. The HEV parallel configuration consists of two separated drive systems, such as the engine/powertrain system and an extra electric motors (EMs) system. The addition of an extra electrical power changes the engine operation point and consequently the fuel consumption. However, there are many ways to introduce this electrical power source as a secondary drive system. In this paper, two parallel HEV configurations are studied in a condition where the conventional engine/powertrain system, coupled to the vehicle front wheels, is the main power source and two different configurations of EMs drive system, coupled to the rear wheels, are auxiliary power sources. The first one consists of two in-wheel motors coupled directly to the vehicle rear wheels and the other one is an EM coupled to a differential system similar to the existent in the conventional vehicle powertrain. The aim of this paper is to simulate and compare the HEV behavior with the conventional vehicle behavior, both of them running in the Brazilian urban drive cycle NBR6601, evaluating differences in performance, fuel consumption and battery discharging when applicable.
\end{abstract}

\section{INTRODUTION}

The increasing number of cars may be causing serious effects to the environment and to humans, such as pollution, global warming, depletion of oil reserves, among others [1]. Vehicles propelled by combustion engines are probably the prominent fossil fuel consumers around the world [2]. The vehicles propelled only by the internal combustion engine (ICE) present some disadvantages like low energy efficiency, excessive harmful chemical emissions, high noise level and heavy dependence on a single fuel source [3]. The electric vehicles (EV) could be a solution but, until this moment, their present short driving range [4] combined with the long recharging period of theirs batteries postpones their widespread commercialization [5].

The hybrid vehicles use different power sources with various powertrain configurations, including the ICE, electric motors (EMs), electric generators and battery packs [6]. In this paper are studied the hybrid electric vehicles (HEVs) that are one of the solutions proposed to minimize problems associated with the energy crisis and global warming [3]. These vehicles consume less gasoline and emit less pollution than conventional vehicles without decreasing 
performance [7]. The HEVs are designed to minimize the emission of pollutants [8], and also to improve the vehicle acceleration performance, the slope climbing capacity and providing fuel consumption reduction [9]. However the HEVs performance is directly dependent on the power management strategies used to control the power flow between the different subsystems [4].

The HEVs present a power management system (PMS) that splits the power demand between the available power sources, according to the driving condition. The ICE presents low efficiency in transient regimes and idling. The PMS control strategy for the HEVs tries to avoid these regimes by managing the energy sources in order to minimize fuel consumption and emissions [10].

There are several ways to implement power management control, one alternative is the rule based strategies that use heuristic methods, based on the human expertise and even mathematical models [11] and [12]. This rule based control is applied in [13], [14], [15], [16] and [17]. The rules depend on the vehicle power demand that is defined by the vehicle longitudinal dynamics equating that considers the driver requested acceleration and the motion resistance forces. The PMS controls the state of each power source to keep the engine running at low fuel consumption operation point. The PMS also evaluate the battery state of charge $(S o C)$, to avoid high discharges that reduce the range of electrical propulsion and to prevent the complete battery discharge.

This paper studies the HEV parallel configuration where the (EMs) are directly coupled to the vehicle rear wheels as proposed in [1], [16] and [17] without any mechanical connection with conventional ICE/powertrain system that is similar to the conventional vehicle system. According to the experimental results shown in [18] this HEV configuration presents a significant improvement of vehicle fuel consumption as compared with the conventional vehicle, this because the addition of the extra electrical power in the system that allows the engine to run in a different operation point decreasing the fuel consumption.

There are many ways of introducing the extra electrical power source in the vehicle. In this paper are analyzed two different EMs propeller system coupled to the vehicle rear wheels, as proposed in [19] for a pure electric vehicle (EV). The first one consists of two EMs coupled inwheel configuration where the EMs are directly connected to the vehicle rear wheel without any transmission system. The second configuration presents only one EM coupled to a differential (similar to the conventional powertrain system), to propel both rear vehicle wheels.

In order to realize the benefits of HEVs, simulation models are used as the first step in the design development process to analyze and improve the engine fuel economy, vehicle top speed and acceleration performance [16]. In this paper the analyses are based on simulation results obtained by means of co-simulation technique between the multibody dynamics analysis software Adams ${ }^{\mathrm{TM}}$ which contains the vehicle model based on a 1.0L Brazilian vehicle, and Matlab/Simulink ${ }^{\mathrm{TM}}$ where are implemented the vehicle longitudinal dynamics equations and the power management system.

The simulated HEV configurations are submitted to the Brazilian urban driving cycle NBR6601 [20] to represent the driving behavior as proposed in [21]. To create a comparative parameter, the conventional ICE vehicle is also simulated to emphasize the effects of the electrical power addition in the vehicle performance and fuel consumption. 


\section{VEHICLE LONGITUDINAL DYNAMICS}

The vehicle power demand is based on the forces acting during the vehicle displacement as the aerodynamic drag, rolling and climbing resistance, powertrain and longitudinal displacement inertias and the driving behavior that inputs the desired vehicle acceleration [21] and [22]. The vehicle longitudinal dynamics evaluates, by means of equations, the motion resistance forces to define the vehicle required power to reach the drive desired speed. In this paper it will be used the longitudinal vehicle dynamics methodology proposed by [23] whose model is based on the motion resistances forces as shown in Figure 1.

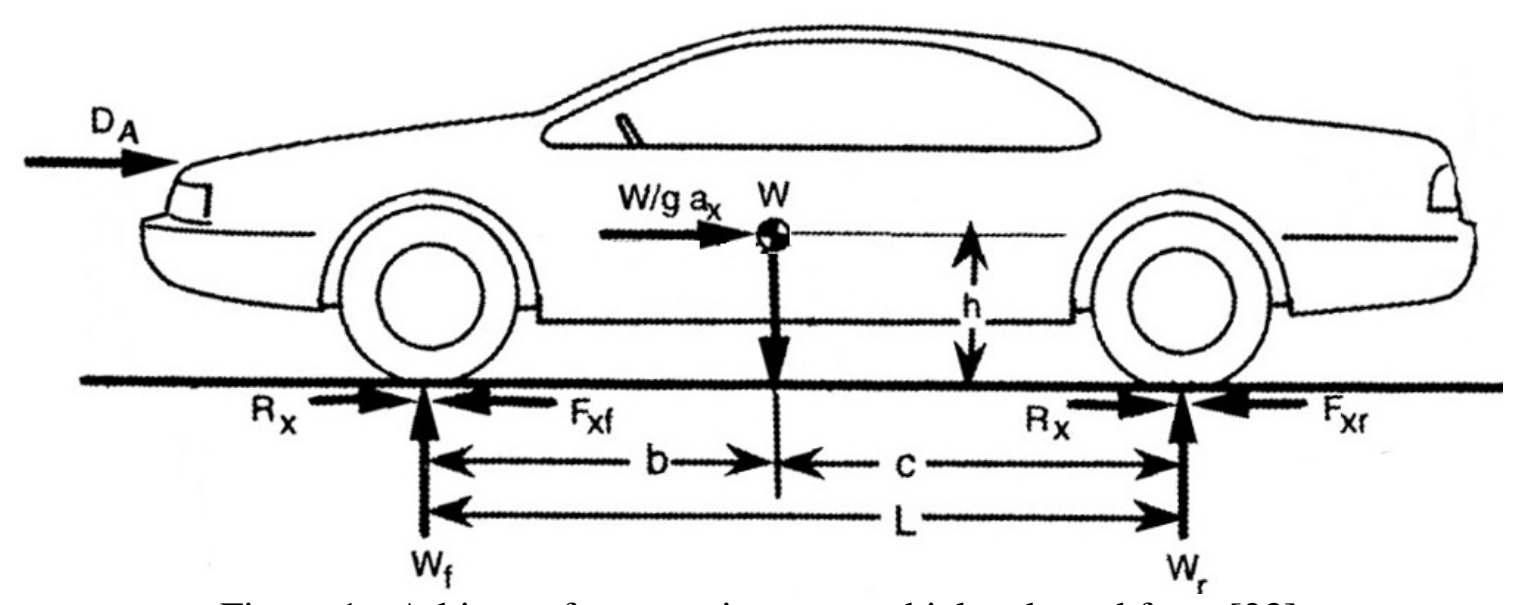

Figure 1 - Arbitrary forces acting on a vehicle adapted from [23]

The rolling resistance $(R x)[\mathrm{N}]$ correspond to the energy loss in the tire due to the deformation at the tire contact area, ground adhesion phenomenon and the rubber damping properties. At low speeds on hard pavement, the rolling resistance is the primary resistance load. The rolling resistance is calculated by the Equation (1) as a function of the vehicle weight $(W)[\mathrm{N}]$ and the vehicle speed $(\mathrm{V})[\mathrm{m} / \mathrm{s}]$.

$\mathrm{R}_{\mathrm{x}}=0.01\left(1+\frac{0.62 \mathrm{~V}}{100}\right) \mathrm{W}$

At high speeds, the air resistance imposed by the vehicle passage becomes responsible for the major parcel of the vehicle power demand. The aerodynamic drag $\left(D_{A}\right)[\mathrm{N}]$, is calculated by the Equation (2) as a function of the air density $\rho\left[\mathrm{kg} / \mathrm{m}^{3}\right]$, the vehicle frontal area $A\left[\mathrm{~m}^{2}\right]$ and the drag coefficient $\left(C_{d}\right)$ that is an empirical constant depending on the vehicle shape.

$D_{A}=\frac{1}{2} \rho V^{2} C_{d} A$

The climbing resistance corresponds to the gravitational force component parallel to the road plane. When the vehicle is at uphill state, the climbing resistance force acts against the movement. On the other hand, at downhill state, this force acts in favor of the movement [23]. The grade angle also influences the weight force component parallel to the ground which, as in the case of accelerating or braking on flat ground, results in a longitudinal weight transfer [24]. Thus, this paper is based on the NBR6601 driving cycle. The climbing resistance is disregarded in the vehicle power demand calculation because the standard cycle does not provide information about the road grade and it is considered null during the cycle. 
The vehicle longitudinal displacement and the powertrain rotational inertia also generate resistance forces. For a conventional vehicle propelled only by the ICE/powertrain system, the available traction force $(F x f)[\mathrm{N}]$ at the vehicle wheels is a function of the engine torque $\left(T_{e}\right)[\mathrm{Nm}]$, the gearbox $\left(N_{t}\right)$ and differential $\left(N_{d}\right)$ transmission ratios and the powertrain overall efficiency $\left(\eta_{t d}\right)$ as shown in Equation (3).

$F_{x f}=\frac{T_{e} N_{t} N_{d} \eta_{t f}}{r}-\left(\left(I_{e}+I_{t}\right)\left(N_{t} N_{d}\right)^{2}+I_{d} N_{d}^{2}+I_{w}\right) \frac{a_{x}}{r^{2}}$

- $\quad r=$ Tire effective radius

- $I_{e}=$ Engine inertia

- $I_{t}=$ Gearbox inertia

- $I_{d}=$ Differential inertia

- $I_{w}=$ Wheels and Tires inertia

$\left[\mathrm{kgm}^{2}\right]$

- $a_{x}=$ Vehicle longitudinal acceleration

The vehicle acceleration $\left(a_{x}\right)\left[\mathrm{m} / \mathrm{s}^{2}\right]$ is given by the available traction force $\left(F_{x}\right)$ [N] (from all the vehicle wheels $\left.F_{x}=F_{x f}+F_{x r}\right)$ and the movement resistance forces $\left(\mathrm{R}_{\mathrm{x}}\right)[\mathrm{N}]$ and $\left(D_{A}\right)[\mathrm{N}]$ as shown in Equation (4).

$a_{x}=\frac{F_{x}-R_{x}-D_{A}}{M}$

The vehicle requested acceleration $\left(a_{r e q}\right)\left[\mathrm{m} / \mathrm{s}^{2}\right]$ is given by the Equation (5) as the difference between the current vehicle speed $(V)$ [m/s] and the NBR6601 requested speed $\left(V_{c}\right)[\mathrm{m} / \mathrm{s}]$ according to the simulation step size $(d t)[\mathrm{s}]$.

$a_{r e q}=\frac{V_{c}-V}{d t}$

To estimate the engine required torque for a predetermined situation, the vehicle requested acceleration $\left(a_{r e q}\right)\left[\mathrm{m} / \mathrm{s}^{2}\right]$ must be used instead of the current acceleration $\left(a_{x}\right)\left[\mathrm{m} / \mathrm{s}^{2}\right]$ so that the vehicle can reach the desired cycle speed at the end of the simulation step. The Equation (6) merges the Equations (3) and (4) considering a vehicle propelled only by the front wheels $\left(F_{x}=F_{x f}\right)$. The engine torque $\left(T_{e}\right)[\mathrm{Nm}]$ is isolated and it represents the requested torque $\left(T_{r e}\right)[\mathrm{Nm}]$ necessary to accelerate the vehicle until the cycle speed.

$T_{r e}=\frac{\left(M a_{r e q}+\frac{\left(\left(I_{e}+I_{t}\right)\left(N_{t} N_{d}\right)^{2}+I_{d} N_{d}^{2}+I_{w}\right) a_{r e q}}{r^{2}}+R_{x}+D_{A}\right) r}{N_{t} N_{d} \eta_{t d}}$

Because of the parallel HEV configuration, EMs are directly coupled to the rear wheels while the engine/powertrain system is connected to the front wheels. HEV needs to know the required torque at the vehicle wheels [17]. The wheels torque $\left(T_{w}\right)[\mathrm{Nm}]$ is defined by the Equation (7).

$T_{w}=T_{e} N_{t} N_{d} \eta_{t d}$

The requested torque at the vehicle wheels $\left(T_{r w}\right)[\mathrm{Nm}]$ is calculated by the union of the Equations (6) and (7) as shown in Equation (8). 
$T_{r w}=\left(M a_{r e q}+\frac{\left(\left(I_{e}+I_{t}\right)\left(N_{t} N_{d}\right)^{2}+I_{d} N_{d}^{2}+I_{w}\right) r e q}{r^{2}}+R_{x}+D_{A}\right) r$

The PMS divides the required wheel torque $\left(T_{r w}\right)$ between the available power sources. The PMS algorithm defines the best system to propel the vehicle according to the situation. The torque at the vehicle wheels is given by the sum of the ICE/powertrain torque $\left(T_{I C E w}\right)[\mathrm{Nm}]$ and the EMs torque $\left(T_{E M w}\right)[\mathrm{Nm}]$ as shown in Equation (9).

$T_{r w}=T_{I C E w}+T_{E M w}$

After the power management system divides the requested torque $T_{r w}[\mathrm{Nm}]$ for each drive system, the EMs required torque $\left(T_{r M E}\right)$ is calculated by the Equation (10) (if the EMs are coupled in-wheel) as a function of the electric motor efficiency $\left(\eta_{M E}\right)$ because in the in-wheel configuration the EMs are not coupled in the vehicle front wheels powertrain.

$T_{r M E}=\frac{T_{E M w}}{\eta_{M E}}$

If the EM is coupled to the rear wheels by a differential transmission system, the EM requested torque $\left(T_{r M E}\right)[\mathrm{Nm}]$ is given by the Equation (11) that considers the differential transmission ratio $\left(N_{d}\right)$ and the mechanical efficiency $\left(\eta_{t d}\right)$ that are similar to the presented in the conventional vehicle powertrain.

$T_{r M E}=\frac{T_{E M w}}{N_{d} \eta_{t d} \eta_{M E}}$

The parcel of the torque demand destined to the engine $\left(T_{\text {rICE }}\right)$ is given by the Equation (12) that considers the differential transmission ratio $\left(N_{d}\right)$ and also the gearbox ratio $\left(N_{t}\right)$ that varies according to the selected gear.

$T_{\text {rICE }}=\frac{T_{I C E w}}{N_{t} N_{d} \eta_{t d}}$

During the gear shifting process, the clutch is responsible for decoupling the engine from the rest of the powertrain [21] and [25]. Because of this, the vehicle speed presents a decrease due to the torque interruption at the front drive wheels. After the clutch recoupling, the vehicle needs to increase the acceleration to return to the desired speed and it increases the engine fuel consumption. In this paper, the clutch maximum transmissible torque during the gear shifting process $\left(T_{C L}\right)[\mathrm{Nm}]$ is defined by the Equation (13) proposed by [26].

$T_{C L}=\frac{2}{3} \mu_{c l} F_{n} n \frac{R_{o}{ }^{3}-R_{i}{ }^{3}}{R_{o}{ }^{2}-R_{i}{ }^{2}}$

- $\mu_{c l}=$ Clutch friction coefficient

- $n=$ Clutch number of faces

- $R_{o}=$ Clutch external disk radius

[m]

- $\quad R_{i}=$ Clutch inner disk radius

The force applied between the discs $\left(F_{n}\right)[\mathrm{N}]$ is established according to the graphic method presented in [27] which is based on the parameters proposed in [28] for a 1.0L engine vehicle. 
The shift duration must be short to prevent energy dissipation caused by the torque supply interruptions [29]. In this paper is used the estimated gear shift time of 1 second as proposed by [30]. The initial $0.3 \mathrm{~s}$ are used so that the engine gets to complete decoupling from the gearbox. The gearbox changes the transmission ratio and synchronizes the engine and the target gear speeds in the next $0.2 \mathrm{~s}$ to gradually recoupling the clutch discs increasing the transmittable torque until the driver demand level [31] during the remaining $0.5 \mathrm{~s}$.

According to [32] the shift quality is determined by the gear shifting strategy that defines the appropriate moment to execute the shift. In this paper is used the gear shifting speeds proposed in [33] for a vehicle similar to the simulated at the conventional configuration. Due to the speed decrease caused by the engine decoupling during the gear shifting, [34] proposes that the downshift speed must be $5 \mathrm{~km} / \mathrm{h}$ lower than upshift speed to avoid gear shifting instability.

The vehicle acceleration performance is limited by two factors: restricted traction at start-up condition and low speed and available power to propel the vehicle [23] and [35]. The vehicle traction limit is modeled as proposed in [36].

The vehicle acceleration or braking process on flat ground results in a longitudinal weight transfer [24]. In vehicles propelled by the frontal wheels, the weight transferred during the vehicle acceleration can reduce the tire-ground maximum transmissible force $\left(F_{x f(\max )}\right)[\mathrm{N}]$ and decrease the vehicle performance as demonstrated in [22]. On the other hand, the rear tires traction limit $\left(F x_{r(\max )}\right)[\mathrm{N}]$ increases with the vehicle acceleration. At brake condition these effects are reversed. The Equations (14) and (15) show the maximum tire transmissible force $\left(F_{x(\max )}\right)[\mathrm{N}]$ for the vehicle frontal and rear wheels according to the tire-ground peak coefficient of friction $(\mu)$.

$$
\begin{aligned}
& F_{x f(\max )}=\mu W_{f} \\
& F_{x r(\max )}=\mu W_{r}
\end{aligned}
$$

As proposed by [36], the weight force acting on the vehicle frontal $W_{f}[\mathrm{~N}]$ and rear $W_{r}[\mathrm{~N}]$ axles is calculated by the Equations (16) and (17) respectively.

$$
\begin{aligned}
& W_{f}=\frac{W c}{2 L}-\frac{W h a_{x}}{2 L g} \\
& W_{r}=\frac{W b}{2 L}+\frac{W h a_{x}}{2 L g}
\end{aligned}
$$

- $L=$ Wheelbase

- $h=$ Vehicle gravity center height

- $g=$ Gravity

- $\quad \mathrm{b}=$ Longitudinal distance between the vehicle front axle and the gravity center

- $c=$ Longitudinal distance between the vehicle rear axle and the gravity center

If the performance is limited by one of the tire traction limits, the vehicle acceleration is calculated by the Equation (4) replacing the available traction force by for the maximum tire transmissible force $\left(F_{x(\max )}\right)[\mathrm{N}]$ according to the Equation (18). In that situation, the vehicle 
acceleration decreases and consequently the applied weight force at the vehicle wheels changes. Where $F_{x f}$ represents the frontal wheels available traction force from the ICE/powertrain system and $F_{x r}$ is the rear wheels available traction force from the electrical power system (inwheel or differential system).

$$
F_{x}=\left\{\begin{array}{lllll}
F_{x f}+F_{x r} & \text { if } & F_{x f} \leq F_{x f(\max )} & \text { and } & F_{x r} \leq F_{x r(\max )} \\
F_{x f(\max )}+F_{x r} & \text { if } & F_{x f}>F_{x f(\max )} & \text { and } & F_{x r} \leq F_{x r(\max )} \\
F_{x f}+F_{x r}(\max ) & \text { if } & F_{x f} \leq F_{x f(\max )} & \text { and } & F_{x r}>F_{x r(\max )} \\
F_{x f(\max )}+F_{x r(\max )} & \text { if } & F_{x f}>F_{x f(\max )} & \text { and } & F_{x r}>F_{x r(\max )}
\end{array}\right\}
$$

Thus it is generated a loop among the Equations (4), (14) (15), (16) and (17) until the convergence of the vehicle acceleration $\left(a_{x}\right)\left[\mathrm{m} / \mathrm{s}^{2}\right]$ and the tire traction limit conditions.

\section{VEHICLE PROPELLING SYSTEMS}

The simulated HEV is propelled by two independent power sources. The engine/powertrain system similar to the conventional vehicle at the front wheels, and the electrical system coupled to the rear wheel that act as a supplementary propelling system or principal power source at lower power demand.

The engine model is based on lookup table's values that contain the engine torque and fuel consumption data. The torque curves represents the available engine torque in function of the requested throttle and engine speed as shown in Figure 2 a). If the requested engine torque $\left(T_{\text {rICE }}\right)[\mathrm{Nm}]$ calculated by the Equation (12) overcomes the $100 \%$ throttle engine curve, the output torque value will be the maximum available torque and the vehicle performance will probably decrease.

a)

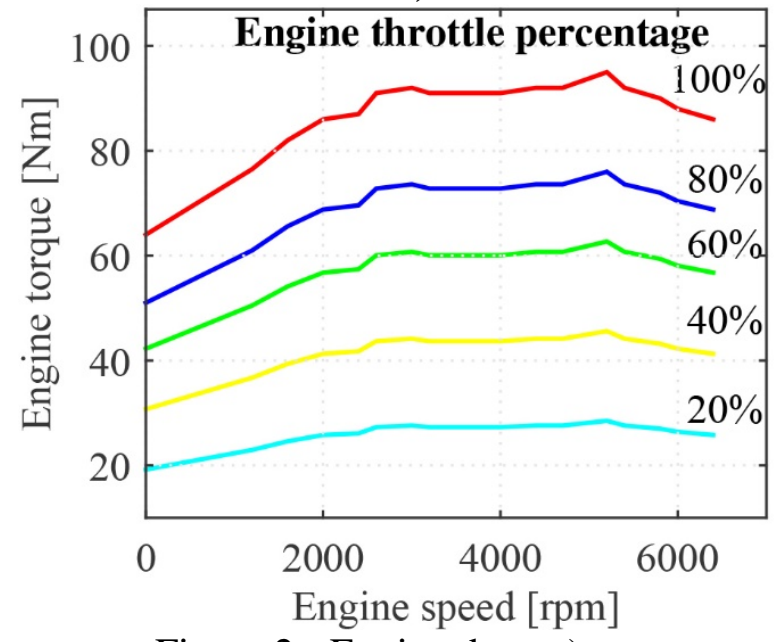

b)

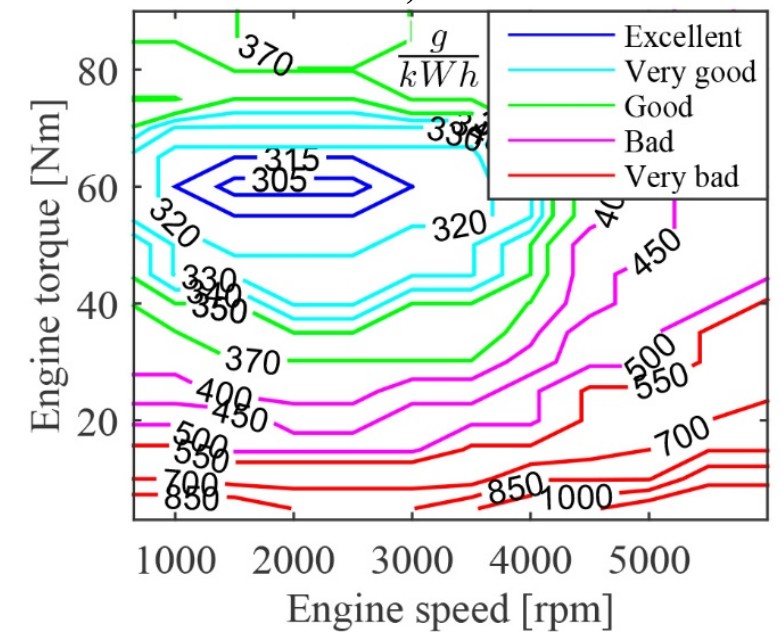

Figure 2 - Engine data: a) torque curves and b) specific fuel consumption map

In this paper it was simulated an Otto cycle gasoline 1.0L engine, and the volumetric fuel consumption $C_{l}[\mathrm{l}]$ is calculated by the Equation (19), as a function of the simulation step $d t$ [s] engine power $P_{e}[\mathrm{~kW}]$, the fuel density $\rho_{f}[\mathrm{~kg} / \mathrm{m} 3]$ and the fuel specific consumption $C_{e}[\mathrm{~g} /(\mathrm{kWh})]$ obtained from the consumption map (Figure $\left.2 \mathrm{~b}\right)$ ). 


$$
C_{l}(d t)=C_{e} \frac{P_{e} d t}{\rho_{f}}
$$

The total volumetric fuel consumption $\left(C_{T}\right)[1]$ is given by the sum of all the step consumptions according to the cycle size $\left(T_{C}\right)$ [s] as shown in Equation (20).

$$
C_{T}=\sum_{d t=0}^{d t=T_{C}} C_{l}(d t)
$$

The EMs were modeled according to the dynamic equations for a DC electric machine with independent field. The Equation (21) shows the relationship between the armature current $\left(I_{a}\right)[\mathrm{A}]$ and the electrical torque $\left(T_{e l}\right)[\mathrm{Nm}]$ according to the torque constant $\left(K_{T}\right)$.

$T_{e l}=K_{T} I_{a}$

The armature current $\left(I_{a}\right)$ [A] is calculated by the Equation (22) as a function of the armature voltage $\left(V_{t}\right)[\mathrm{V}]$, the armature inductance $\left(L_{a}\right)[\mathrm{mH}]$, the armature resistance $\left(r_{a}\right)[\Omega]$ and the back $\operatorname{EMF}\left(E_{a}\right)$.

$I_{a}(s)=\frac{V_{t}(s)-E_{a}(s)}{r_{a}+s L_{a}}$

The Electric motor angular speed $(\omega)[\mathrm{rad} / \mathrm{s}]$ is given by the Equation (23) as a function of the EM inertia $(J)\left[\mathrm{kgm}^{2}\right]$, the charge torque $\left(T_{\text {charge }}\right)[\mathrm{Nm}]$ and the damping constant $D$.

$\omega(s)=\frac{T_{e l}(s)-T_{\text {charge }}(s)}{D+s J}$

The block diagram at the Figure 3 represents the union of the Equations (22) and (23) as proposed by [37]. The EM controller uses a proportional and integral (PI) that generates the armature circuit voltage value $V t(s)[\mathrm{V}]$ of the Equation (22). The error obtained from the difference between the armature current value $\left(I_{a}\right)[\mathrm{A}]$ and the current reference value desired (Iref $(s))[\mathrm{A}]$ is the controller input.

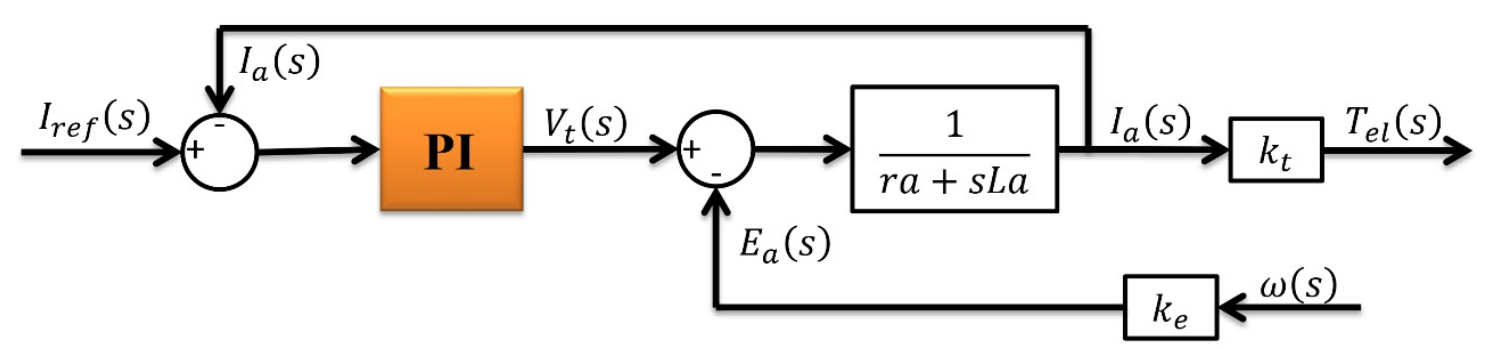

Figure 3- DC electrical motor block diagram adapted from [37]

The required direct demand of the armature current $\left(I_{a}\right)[\mathrm{A}]$ that enables the motor to reach the requested power demand is defined as the reference current (Iref $(s)[\mathrm{A}])$. This control is necessary when the $\operatorname{Ia}(s)$ [A] is equal to $\operatorname{Ire} f(s)$ [A]. In this situation, the controller integrative component is necessary to minimize the EM error to zero when $V t(s)$ [V] it is constant.

The constants used for solving the EM modeling are: $K_{T}=1.98$ [Vs/rad], $r a=0.082[\Omega]$ and $L a=2[\mathrm{mH}]$. In this paper will be studied two EMs with $12 \mathrm{~kW}$ (200 Nm, 1500 maximum rpm) shown in Figure 4 a) and 5 kW (50 Nm, 4000 maximum rpm) Figure 4 b). 
The EMs efficiency is also considered in the calculation of the EMs power consumption. The Figure 4 shows the efficiency regions of the EMs where is possible to observe that the best efficiency is located at the EMs high speeds. At the startup condition, the EM presents the worst efficiency.

a)

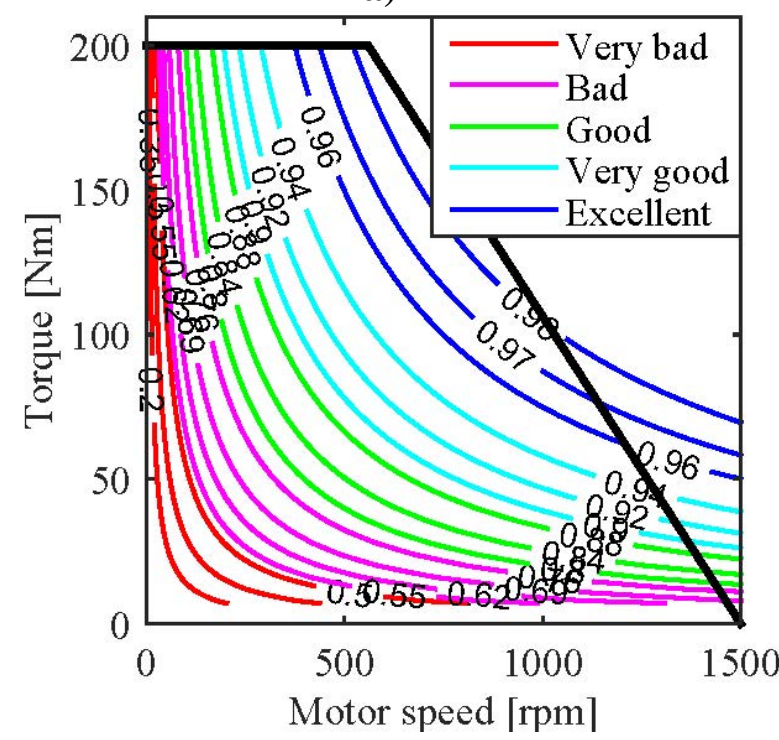

b)

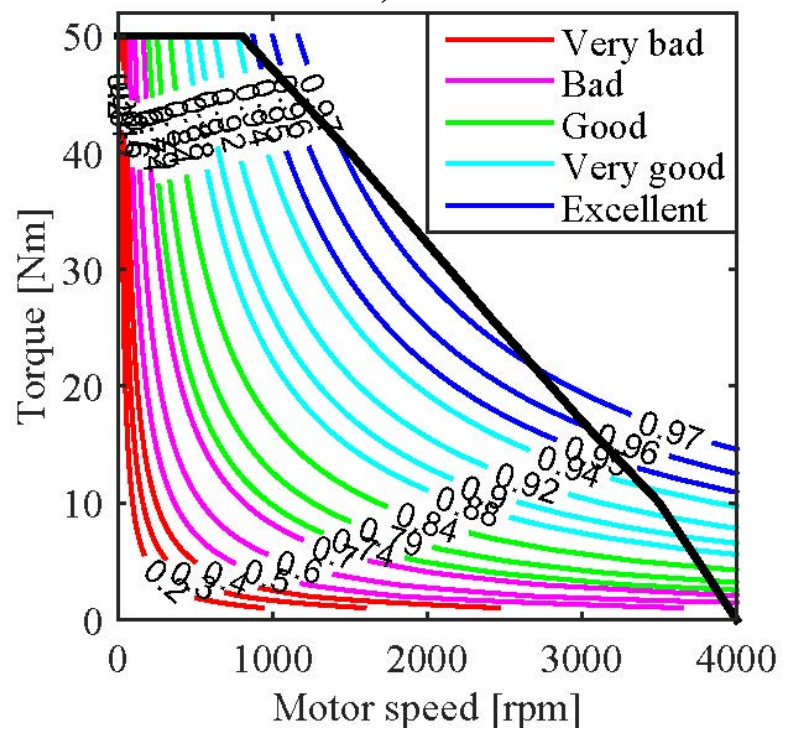

Figure 4 - EMs efficiency: a) $12 \mathrm{~kW}$ and b) $5 \mathrm{~kW}$

When the vehicle is in braking mode, the EMs are able to act as generators converting the kinetic energy into electricity that is stored in the batteries to be used in a future acceleration process [38]. The regenerative braking system allows the vehicle to recover the kinetic energy during deceleration [39]. However, not all the available energy are used to charge the battery. In this paper the EMs regeneration capacity will be considered as $20 \%$ of the maximum torque curve of each EM (

Figure 4). When the maximum EMs regeneration capacity is reached, the remaining brake requested torque is supplied by the frictional mechanical brake system that guarantees the vehicle deceleration performance [40].

The EMs are also coupled to the vehicle by two different ways (in-wheel and differential), the combinations of EMs and coupling configurations totalize $4 \mathrm{HEV}$ configurations and also the standard conventional vehicle as shown in Figure 5.

The Figure 6 shows the available torque at the vehicle wheels according to the coupling configurations. The in-wheel configuration connects the EMs directly to the wheels. Due to this, the available torque at the wheels is the double of the EM output torque because there is one EM coupled in each vehicle rear wheel. As used at the in-wheel configuration, the EMs reach the null torque in a determined high speed which the vehicle cannot reach during the simulated driving cycle as shown in Figure 6 a). In this paper the differential used in the electric propelling system will be considered similar to that one used in the conventional powertrain. When the EM is connected to the vehicle wheels by a differential system, the available torque increases according to the differential transmission ratio $\left(N_{d}\right)$ and the mechanical efficiency $\left(\eta_{t d}\right)$. The EM speed also increases by the transmission ratio $\left(N_{d}\right)$ reaching the higher 
operation speed quickly as shown in Figure $6 \mathrm{~b}$ ). However, the EMs null torque is reached during some cycle sections making impossible its use at highest speeds.

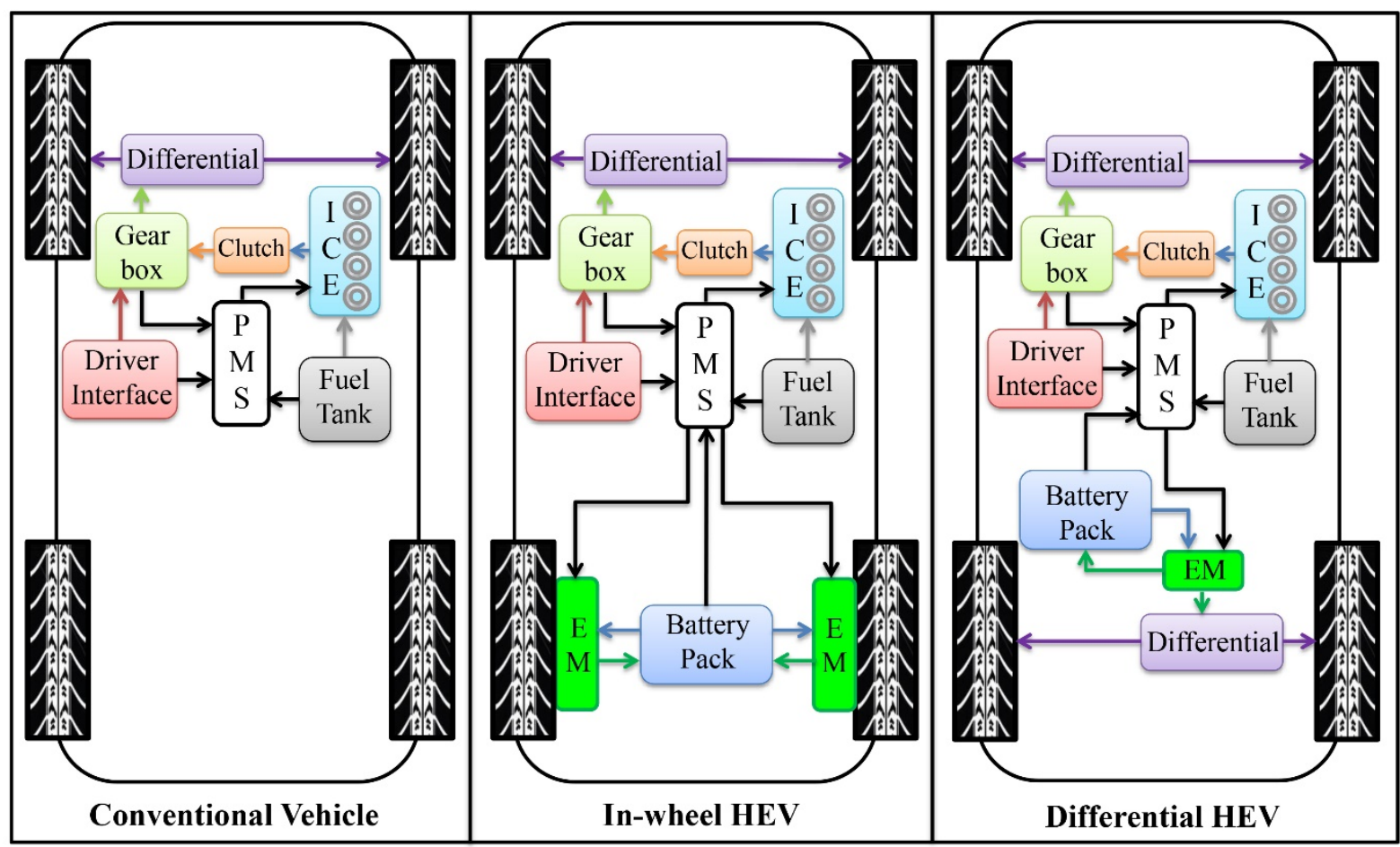

Figure 5 - Simulated vehicle configurations

a)

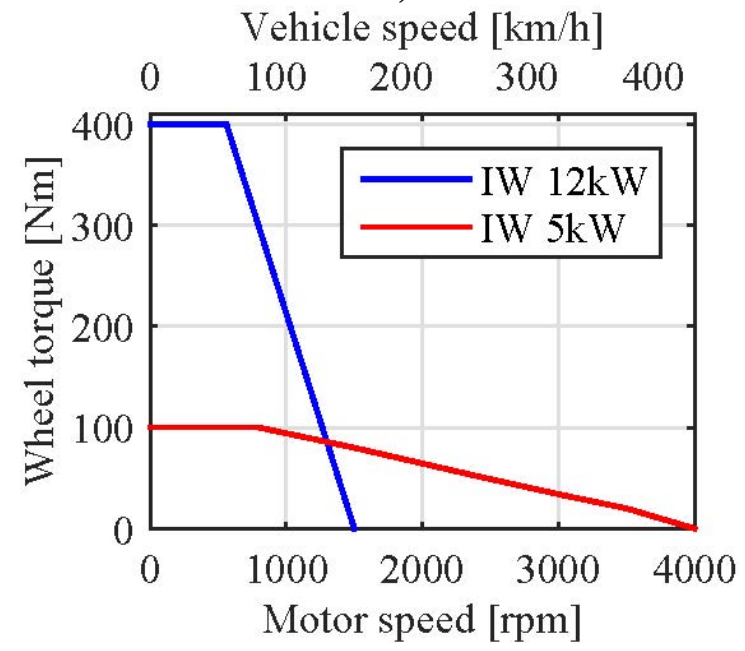

b)

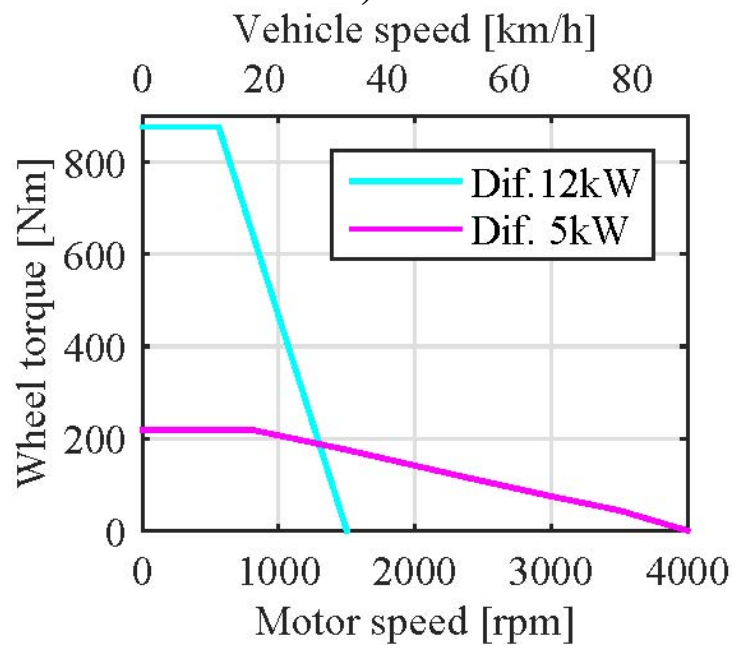

Figure 6 - EMs torque curves according to the coupling configuration: a) In-wheel (IW) and b) Differential (Dif.)

The battery model is a lithium-ion with 20 Ah capacity. The complete batteries discharge will reduce dramatically their life cycle [41]. To prevent the battery complete discharge, the battery state of charge $S o C$ is limited to $40 \%$ of the total possible discharge energy [19]. The SoC can be expressed in (24), as a function of the current $(I)[\mathrm{A}]$ and the batteries capacity $(A h)$ [Ah] according to the time $(t)$ [s].

$\Delta S o C=\frac{1}{A h} \int_{0}^{t} I(t) d t$ 


\section{DRIVING CYCLE}

The standard cycles determine the vehicle speed behavior, during a trip, to calculate the required power by the vehicle to follow the cycle velocity profile. In this paper it is used the standard Brazilian urban driving cycle NBR 6601 [20] as shown in Figure 7. The urban driving conditions are characterized by low speed, low engine load, and low exhaust gas temperature [42]. The cycle has a total distance of $12 \mathrm{~km}$, average speed of $32 \mathrm{~km} / \mathrm{h}, 91.2 \mathrm{~km} / \mathrm{h}$ of maximum speed and the vehicle remains stationary for $17.2 \%$ of the cycle time.

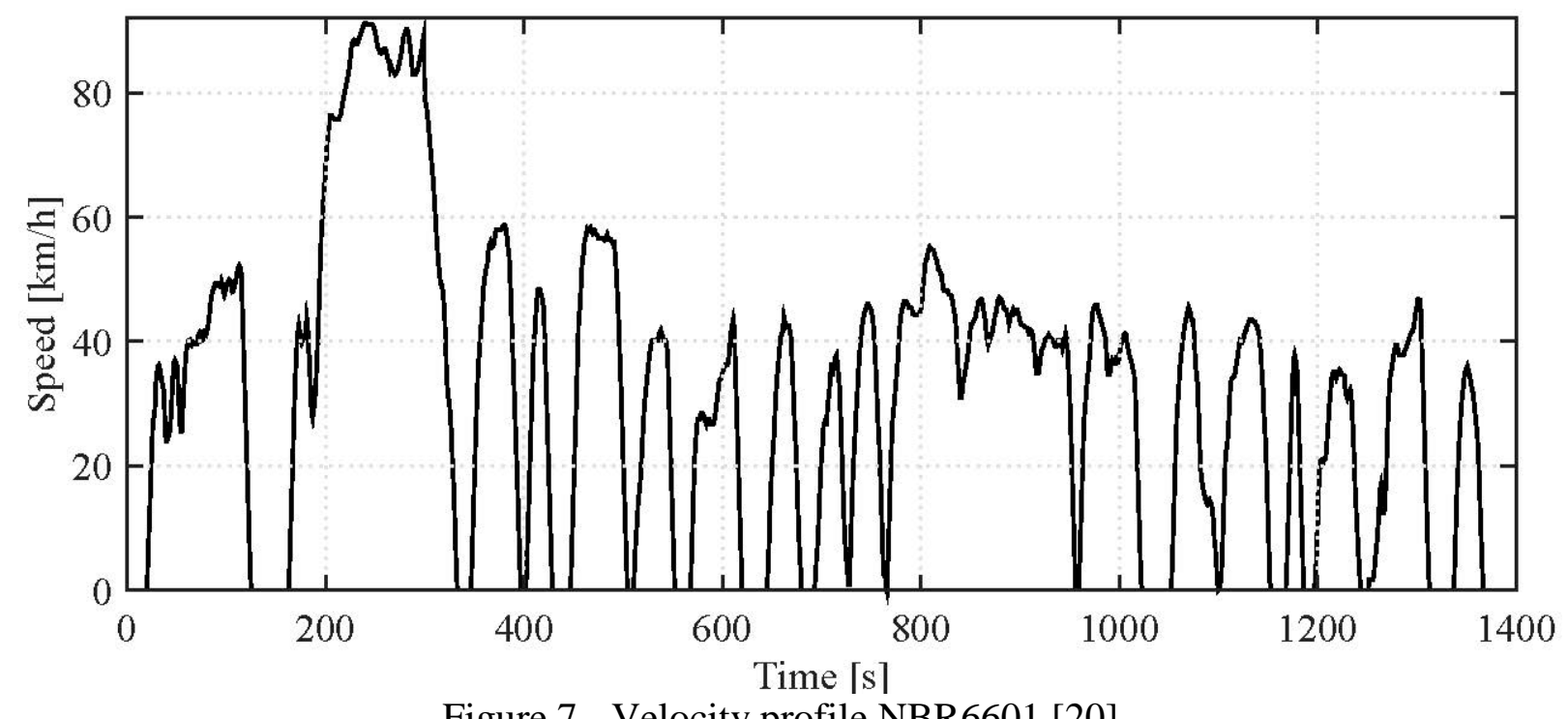

Figure 7 - Velocity profile NBR6601 [20]

\section{CO-SIMULATION}

The co-simulation platform must support the communication between the both software [43]. This technique is used in the development stage in which the physical, mathematical, mechatronic and control systems are designed [44]. According to [45] too much detailed models generate a high computational cost, due to this the Adams ${ }^{\mathrm{TM}}$ model only considers the vehicle longitudinal dynamics. In this paper, the simulations were performed via the multibody dynamic analysis program Adams ${ }^{\mathrm{TM}}$, in which the vehicular model that is based on a dynamometer bench as shown in Figure 8 which also shows the Simulink ${ }^{\mathrm{TM}}$ block that contains the Adams ${ }^{\mathrm{TM}}$ model inputs and outputs used in the co-simulation process.
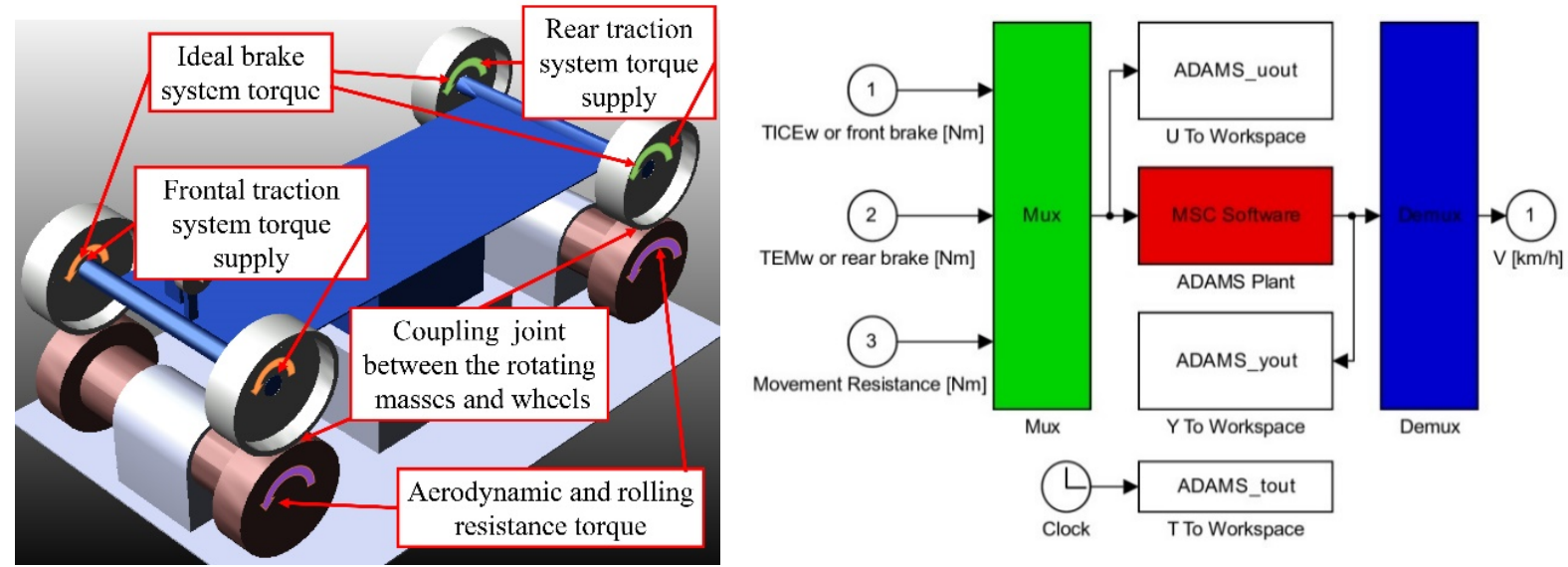

Figure 8 - Adams ${ }^{\mathrm{TM}}$ model [19] and generate Simulink ${ }^{\mathrm{TM}}$ block [17] 
The vehicle chassis was connected to the base making impossible longitudinal movement between the wheels and the rollers that simulate the vehicle longitudinal displacement. The forces and movement between the rollers and the wheels are done by a means of a revolution joint that transmits the torques and acting speeds.

The second software used in the co-simulation is the Matlab/Simulink ${ }^{\mathrm{TM}}$ that allows the creation of the interface between the multibody dynamic model by means of the Adams ${ }^{\mathrm{TM}}$ plugin Adams/Controls ${ }^{\mathrm{TM}}$ which generates a Simulink ${ }^{\mathrm{TM}}$ block (Figure 8) that contains the Adams $^{\mathrm{TM}}$ solver. As a result, the Adams ${ }^{\mathrm{TM}}$ model sends the current vehicle speed as an input to the Simulink ${ }^{\mathrm{TM}}$ that calculates the power demand according to the vehicle parameters from Table 1 and comparing the vehicle speed with the required cycle velocity. Once defined the power demand, the PMS split it between the available propelling systems that sends the respective torques as an input to the Adams ${ }^{\mathrm{TM}}$ block. The movement resistance forces are also an input to the Adams ${ }^{\mathrm{TM}}$ model, they act as a torque against the movement applied to the rollers. With the Simulink ${ }^{\mathrm{TM}}$ inputs, the Adams ${ }^{\mathrm{TM}}$ model updates the vehicle speed and it sends a new input value to the Simulink ${ }^{\mathrm{TM}}$ starting a new simulation step.

Table 1 - Vehicle parameters.

\begin{tabular}{|c|c|c|c|c|c|c|c|c|}
\hline \multirow{2}{*}{ Components } & \multirow{2}{*}{ Units } & \multicolumn{5}{|c|}{ Speed } & \multirow{2}{*}{\multicolumn{2}{|c|}{ Vehicle Geometry }} \\
\hline & & $1^{\text {st }}$ & $2^{\text {nd }}$ & $3^{\text {rd }}$ & $4^{\text {th }}$ & $5^{\text {th }}$ & & \\
\hline Engine inertia & $\mathrm{Kgm}^{2}$ & \multicolumn{5}{|c|}{0.1367} & Vehicle frontal area & $1.8 \mathrm{~m}^{2}$ \\
\hline Gearbox inertia $\left(\times 10^{-4}\right)$ & $\mathrm{Kgm}^{2}$ & 17 & 22 & 29 & 39 & 54 & Drag coefficient & 0.33 \\
\hline Gearbox ratios & - & 4.27 & 2.35 & 1.48 & 1.05 & 0.8 & Wheelbase & $2.44 \mathrm{~m}$ \\
\hline Differential inertia & $\mathrm{Kgm}^{2}$ & & & $22 \mathrm{E}-0$ & & & Gravity center height & $0.53 \mathrm{~m}$ \\
\hline Differential ratio & - & & & 4.87 & & & Rear axle to gravity center & $1.46 \mathrm{~m}$ \\
\hline Wheels + tires inertia & $\mathrm{Kgm}^{2}$ & & & 2 & & & Front axle to gravity center & $0.98 \mathrm{~m}$ \\
\hline Vehicle mass & $\mathrm{kg}$ & & & 980 & & & Tire peak friction coefficient & 0.9 \\
\hline Tires & - & & $175 /$ & /70R & & & Tire radius [m] & 0.2876 \\
\hline
\end{tabular}

\section{PMS - POWER MANAGEMENT SYSTEM}

The power control strategy (PMS) is responsible to split the power demand between both propelling systems. The energy saving in a HEV requires smart configuration design and proper component sizing, and also good control strategy [46].The main issue for HEV design is controlling the energy transfer from sources to the loads with minimum energy loss which depends on the driving cycles [12]. The power control strategy objective is minimizing fuel consumption without sacrificing the vehicle performance [47]. The HEVs performance is tightly dependent on the power management strategies used to control the power flow between the different subsystems [4]. The essence of HEV PMS is determining when and how to use the ICE to fulfill the request output torque (or power) while maintaining battery $S o C$ within a range and minimizing frictional braking [48].

In this paper is used the rule based on heuristic controls proposed in [17], that define the energy source to propel the vehicle according to the PMS strategy which utilizes the electric system to reduce the ICE requested torque, changing the engine operation point and consequently the fuel consumption. When the power demand is low, the electric system acts as the primary propelling system and the ICE/powertrain system is only used when the total requested torque overcomes the maximum available electrical torque at the vehicle rear wheels. 


\section{RESULTS}

The simulations models were divided into three groups according to the propeller system (Figure 5). The first one is the conventional vehicle to establish a benchmark result to be compared with the HEV simulations. The HEVs are divided according to the EM coupling ways as: in-wheel and differential. For each of the HEVs configuration are tested 2 EMs with different torque and operation speed range (Figure 6). Due to the addition of the EMs and battery pack, the HEV total mass increases in $150 \mathrm{~kg}(M=1130 \mathrm{~kg})$. The Table 2 shows the results of the 5 simulated cases.

Table 2 - Simulation results

\begin{tabular}{|c|c|c|c|c|}
\hline $\begin{array}{c}\text { Simulated } \\
\text { Vehicles }\end{array}$ & $\begin{array}{c}\text { Propel System } \\
\text { Configuration }\end{array}$ & $\begin{array}{c}\text { Travel } \\
\text { Distance } \\
{[\mathbf{k m}]}\end{array}$ & $\begin{array}{c}\text { Fuel } \\
\text { Consumption } \\
{[\mathbf{m l}]}\end{array}$ & $\begin{array}{c}\text { Average Fuel } \\
\text { Consumption } \\
{[\mathbf{k m} / \mathbf{l}]}\end{array}$ \\
\hline Conventional & ICE & 11.69 & 1001.0 & 11.68 \\
\hline HEV 5 DIF & ICE +EM (5 kW) differential & 11.91 & 579.0 & 20.57 \\
\hline HEV 12 DIF & ICE +EM (12 kW) differential & 11.99 & 775.5 & 15.46 \\
\hline HEV 5 IW & ICE +2 EMs (5 kW) in-wheel & 11.90 & 525.6 & 22.64 \\
\hline HEV 12 IW & ICE +2 EMs (12 kW) in-wheel & 11.91 & 472.4 & 25.21 \\
\hline
\end{tabular}

The first parameter analyzed was the final travel distance during the vehicle simulation. The NBR6601 was a $12 \mathrm{~km}$ total path, however the simulated vehicles does not reach the total cycle distance. It happens due to the engine torque supply interruption caused by the clutch decoupling in the gear shifting process, that consequently reduces the vehicle speed until the clutch recoupling what allows the vehicle reacceleration to reach the cycle requested speed.

As compared with the conventional vehicle, the simulated HEVs present an improvement of the vehicle performance due to the increase of the final travel distance as shown in Table 2 . This performance improvement happens because the addition of the extra electric propulsion system that acts independently of the ICE/powertrain system. Due to this, during the gear shifting process, the vehicle continues to be propelled by the EMs minimizing the speed decrease, increasing the vehicle displacement and reducing the vehicle requested acceleration to return to the cycle speed. The Figure 9 shows the difference between the conventional and the HEV acceleration performance in some cycle sections.
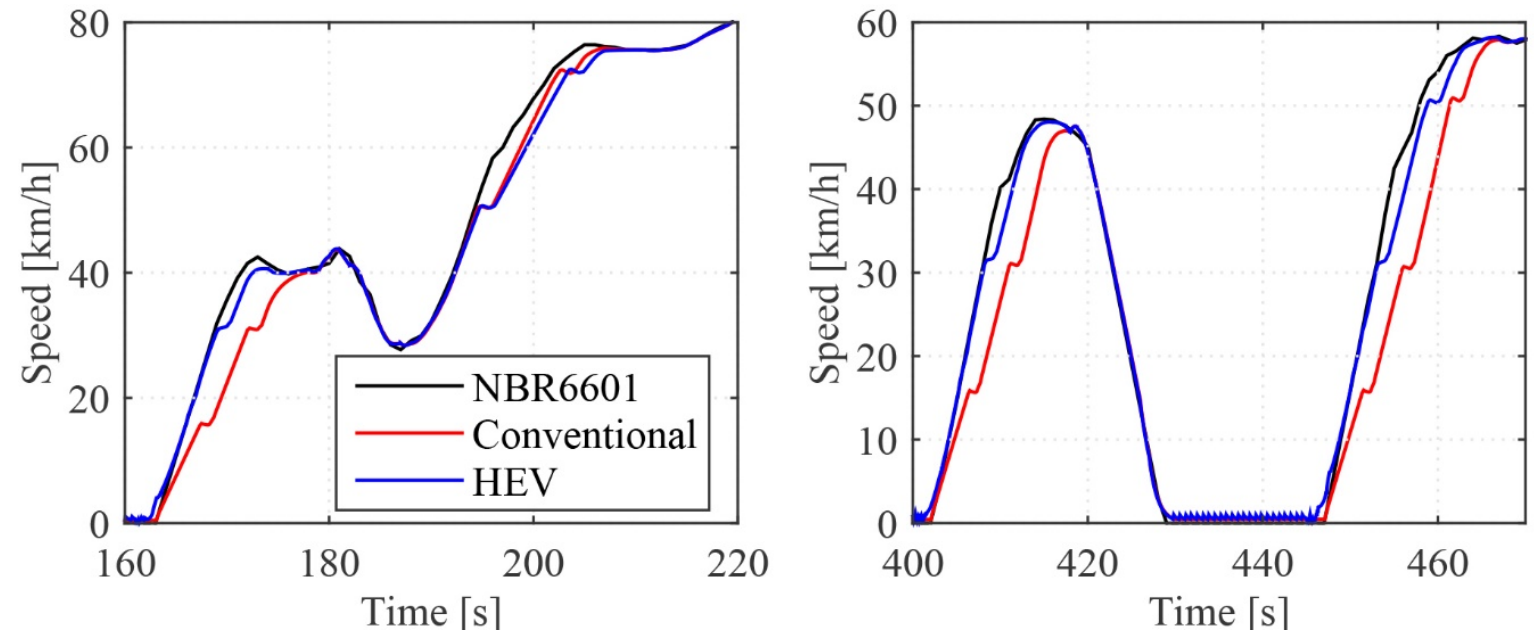

Figure 9 - Vehicle performance improvement 
The longitudinal acceleration transfers a parcel of the vehicle weight to the rear axle. Due to this, the maximum transmissible force between the frontal tires and the ground decreases and the vehicle is unable to apply the requested torque to keep the vehicle at the cycle speed when it is propelled only by the front wheels (ICE/powertrain). At the vehicle rear axle, the traction limit increases with the vehicle acceleration allowing the EMs to transfer more torque to the rear wheels improving the vehicle acceleration. The HEV acceleration performance is better due to the increase of the tire traction limit at the wheels propelled by the electric power and to also because of the continuity of EM torque supply during the gear shifting process.

The HEV simulation results also show a significant reduction of fuel consumption, the results vary according to the combination EM/drive system of the electrical system. In this paper it was used a 20 Ah battery pack limited to $60 \%$ of discharge $\left(S o C_{\max }=40 \%\right)$ what in some simulated cases it was inadequate to fulfill the cycle with electric power until the end of the proposed velocity profile. If the battery reaches the discharge limit, the vehicle is propelled only by the ICE until the battery recharges at least 3\% by regenerative braking. The Figure 10 shows the HEV (5 kW EM+ Differential) drive systems operation during the simulated cycle. This configuration presents a $42.16 \%$ of reduction at the fuel consumption.

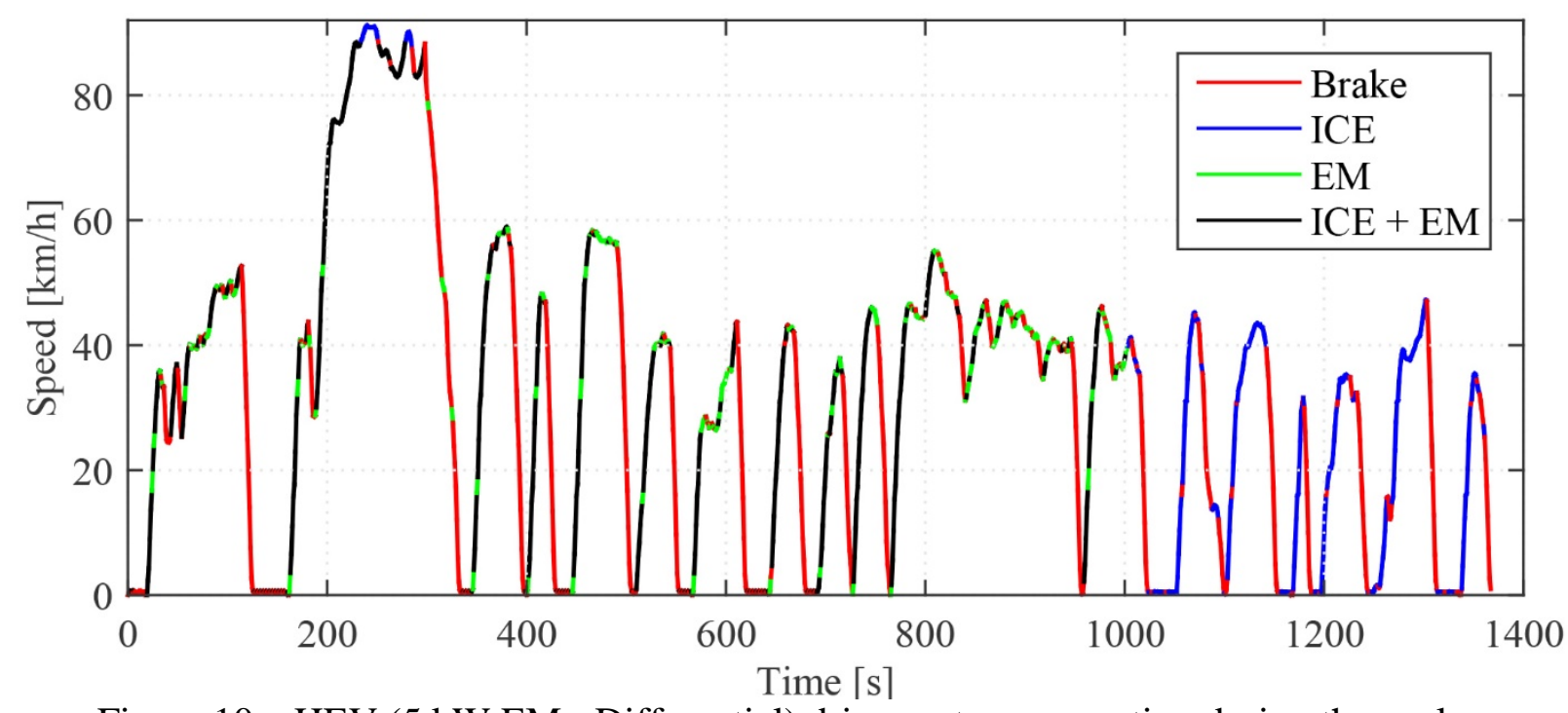

Figure 10 - HEV (5 kW EM+ Differential) drive systems operation during the cycle.

Due to the $5 \mathrm{~kW}$ low torque and high operation speed even as connected to the differential system (Figure $6 \mathrm{~b}$ )), the PMS chooses to propel the vehicle by the combination of the both drive systems (ICE and EM) during the 1000 first seconds of the cycle. After that, the battery reaches the $40 \%$ SoC and the vehicle finishes the cycle using the ICE system. The $5 \mathrm{~kW} E M$ was unable to recharge the battery (in the analyzed configuration) until the minimum value that allows to use it again.

In the configuration shown in Figure 10, the $5 \mathrm{~kW}$ EM reaches the null torque at $89 \mathrm{~km} / \mathrm{h}$ as shown in Figure $6 \mathrm{~b}$ ), this speed limit is only reached in a small section of the cycle ( $240 \mathrm{~s}$ to $300 \mathrm{~s}$ ). When the HEV is simulated with the $12 \mathrm{~kW}$ EM coupled to the differential, the EM reaches the null torque at $36 \mathrm{~km} / \mathrm{h}$. The Figure 11 shows that the $12 \mathrm{~kW}$ EM speed limit is reached in all acceleration section of the cycle. Due to this, the HEV acts as a conventional vehicle when the speed is over $36 \mathrm{~km} / \mathrm{h}$. Thus, the ICE fuel consumption reduction was $22.53 \%$ in this configuration what represents a small value as compared with the others HEV 
configurations. On the other hand, this configuration presents the minimum battery discharge of the studied cases, but the PMS was able to propel the vehicle, only by the EM system, in more cycle stretches due to the higher EM output torque, especially at the startup condition.

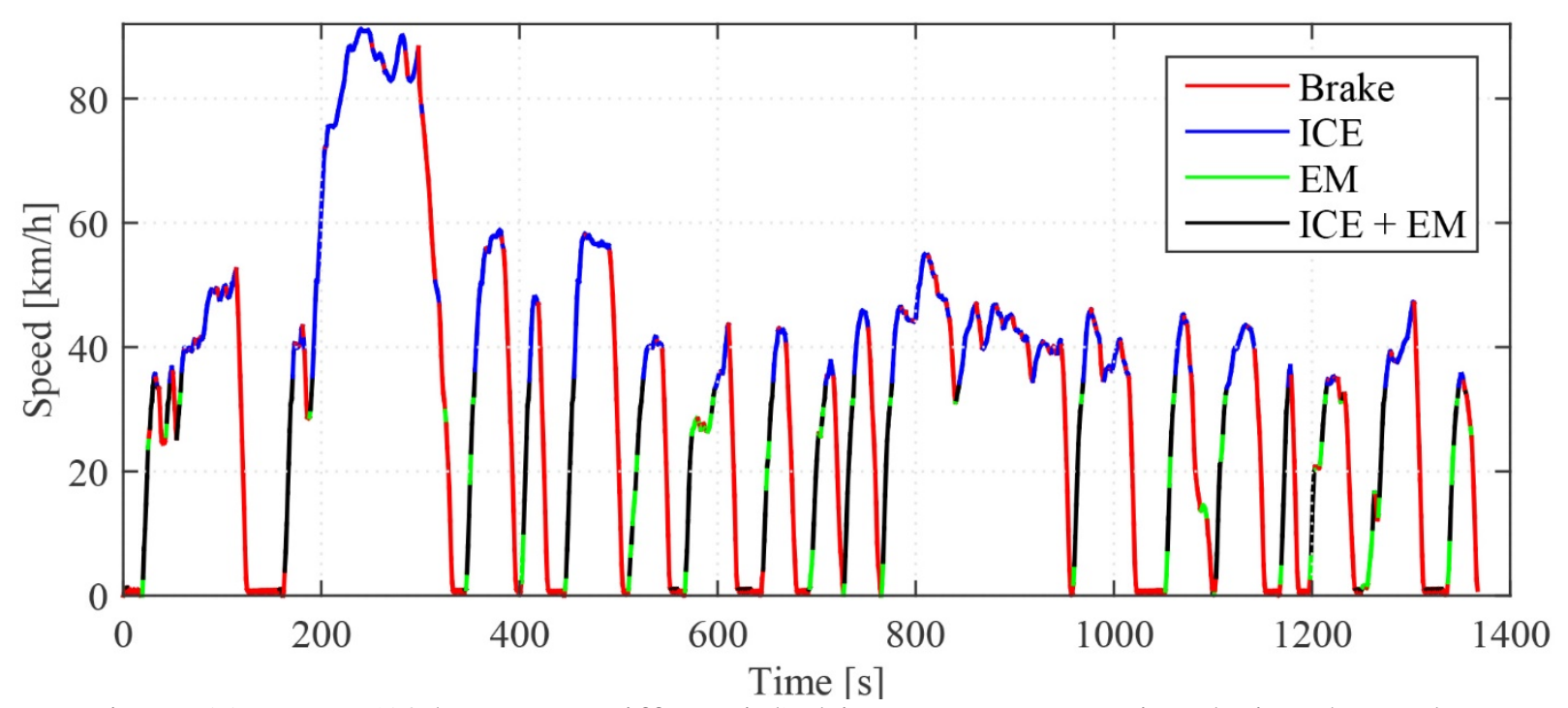

Figure 11 - HEV (12 kW EM+ Differential) drive systems operation during the cycle.

The Figure 12 shows the propelling systems activation profile for the HEV with two $5 \mathrm{~kW}$ EMs connected in-wheel. This configuration presents a $47.49 \%$ improvement of the engine fuel consumption. These EMs provide a small output torque as coupled directly to the vehicle wheels, however they only reach the null torque at very high speed which the vehicle is unable to reach (Figure 6 a)). The PMS uses this EMs combined with the ICE/powertrain system to present the battery charge that only reaches the discharge limit at the end of the cycle.

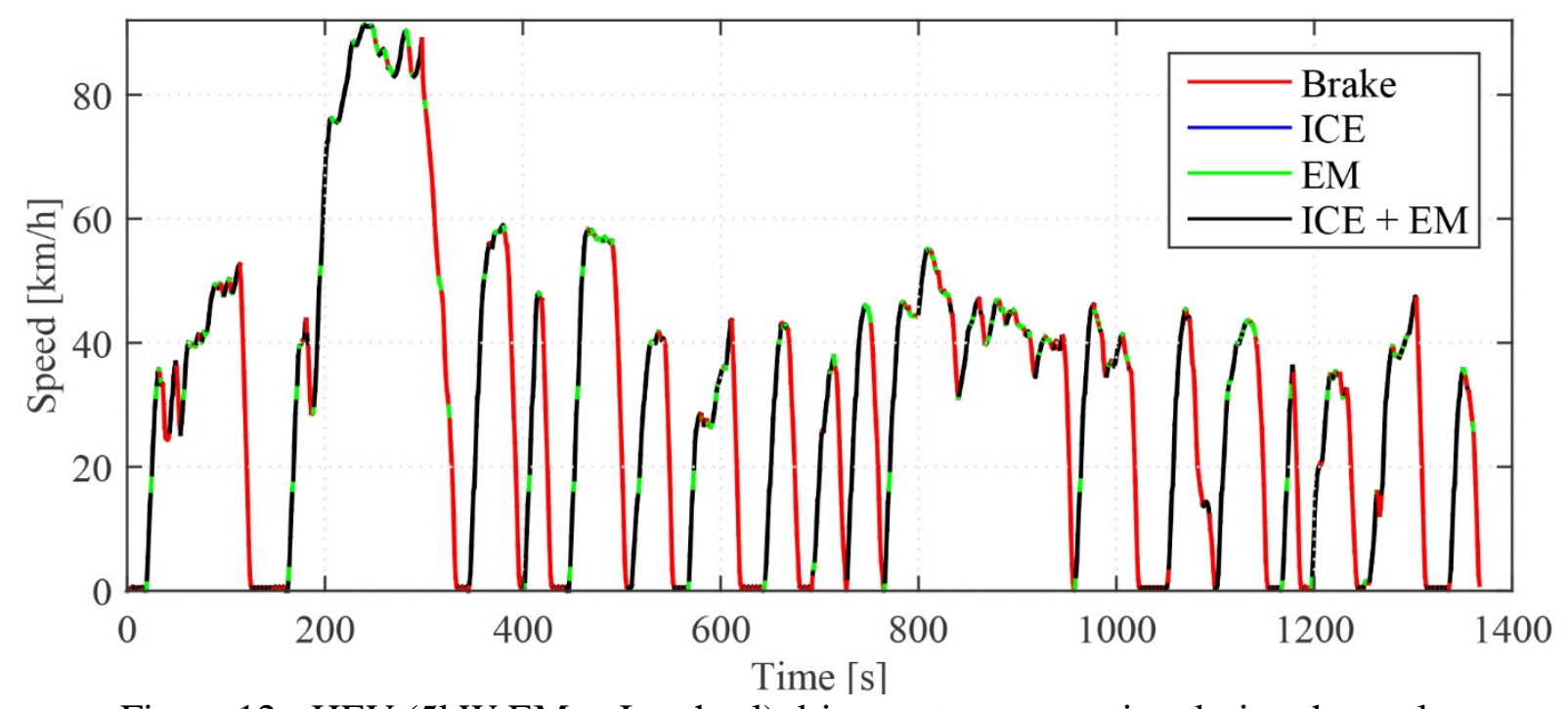

Figure 12 - HEV (5kW EMs+ In-wheel) drive systems operation during the cycle.

The Figure 13 shows the HEV with two in-wheel $12 \mathrm{~kW}$ EMs PMS control profile. This configuration presents the best result among the simulated cases with an ICE fuel consumption improvement of 52.81\%. This configuration reaches the EMs null torque at high speeds $(150 \mathrm{~km} / \mathrm{h})$ that are over the cycle maximum requested speed as shown in Figure $6 \mathrm{a}$ ). Due to the higher output torque of these EMs, the PMS was able to propel the vehicle only by the 
electrical system for the largest sections of the cycle. This behavior saves fuel because the ICE is turned off, however it increases the battery discharges that reach the maximum $S o C$ closer to $600 \mathrm{~s}$ of simulation.

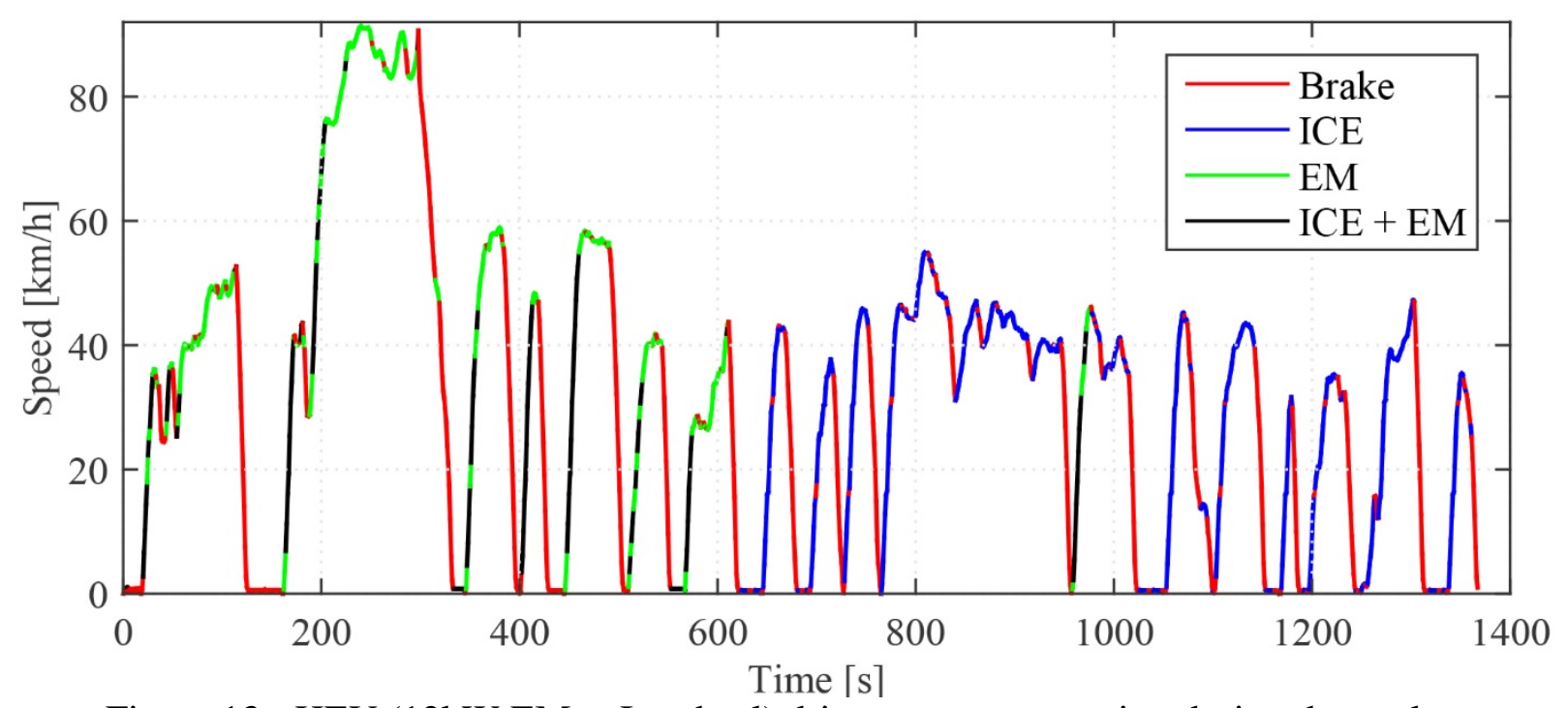

Figure 13 - HEV (12kW EMs+ In-wheel) drive systems operation during the cycle.

In the Figure 13 it is possible to observe that the PMS stops using the EMs system due to the battery discharge has reached the maximum acceptable value at $600 \mathrm{~s}$. However, the $12 \mathrm{~kW}$ EMs (when coupled in-wheel) present the best regenerative braking efficiency, what allows the battery recharge until the minimum value that is possible for the PMS to use the electrical system. This enables the HEV to operate with both drive systems in the acceleration stretch at $960 \mathrm{~s}$ discharging the battery until the limit of $40 \% \mathrm{SoC}$ and disabling the EMs until the end of the cycle. The Figure 14 shows the battery state of charge ( $S o C$ ) behavior according to the HEV configurations to complement the explanation of the PMS control strategies shown previously.

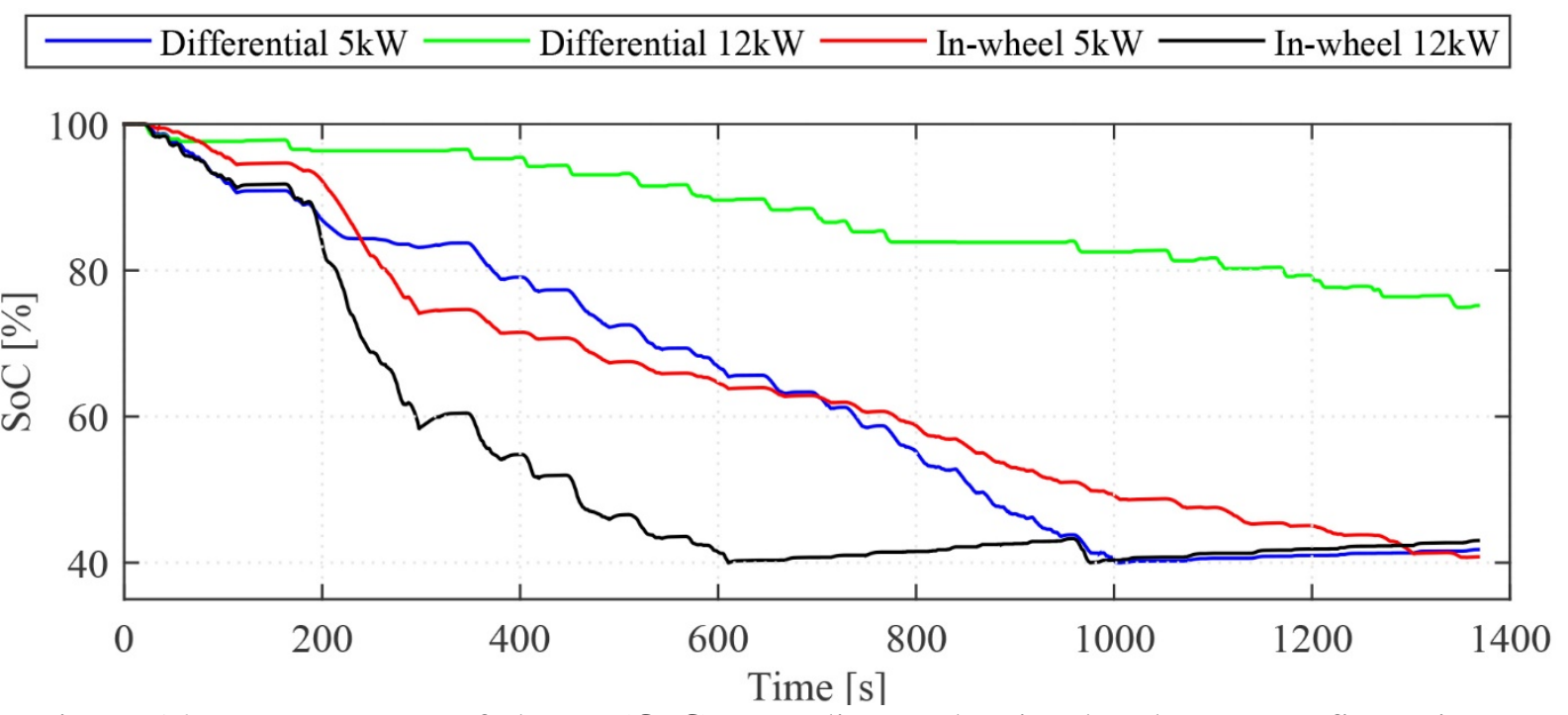

Figure 14 - Battery state of charge $(S o C)$ according to the simulated HEV configuration

The configuration that uses the $12 \mathrm{~kW}$ EM coupled to the differential presents the smaller battery discharge that make possible, for this HEV, to use a small battery pack that could reduce the total vehicle mass and consequently the vehicle power demand. 


\section{CONCLUSION}

In this paper it is studied the influence of different HEVs and they are compared with the conventional vehicle propelled by the ICE. The results are obtained by means of co-simulations between the multibody dynamics analysis software Adams ${ }^{\mathrm{TM}}$ that represents the vehicle longitudinal dynamic model and Matlab/Simulink ${ }^{\mathrm{TM}}$ in which it is implemented the movement resistance forces equations and the vehicle propel systems models.

To create a benchmark among the simulated vehicles it was adopted the Brazilian urban driven cycle NBR6601 as an input to define the driver behavior of the vehicle requested acceleration. The first simulation considers the conventional vehicle that is propelled only by the ICE/powertrain system. More two parallel HEV configurations (in-wheel and differential) with two EMs and also different torque and operation speed range were simulated.

The simulations evaluated the vehicle performance as compared with the standard driving cycle, the fuel consumption, and the battery discharge behavior according to the vehicle configuration and PMS strategy.

The HEVs configurations present an acceleration performance improvement as compared with the conventional vehicle even with the increase of the vehicle mass due to the addition of the EMs system and battery pack. The fuel consumption also presents a significant improvement (52.81\%. - the best reached result). However, in this paper the battery pack starts the cycle fully charged and the cost of the electric energy used to charge the battery was not considered in the HEV overall system. Therefore, the reduction of fuel consumption had been compensated based on the initial electrical system charge cost to estimate the real gain of the HEV as compared with the conventional vehicle.

The regenerative braking also was considered in the simulations. According to the combination of EM/coupling system, the EMs present different behaviors to convert the vehicle kinetic energy during the braking process in electrical energy used to recharge the battery. The inwheel configuration presents the best regenerative efficiency because in this configuration they were used 2 EMs instead of a single EM with differential.

The HEVs are an alternative to reduce the vehicle fuel consumption because the addition of the electrical power source enables to operate the engine at a different point, salving fuel. The extra electrical EMs, coupled to the vehicle rear wheels, also improved the vehicle acceleration performance, reducing the performance decrease due to the tire traction limitation and the lack of torque caused by the clutch decoupling during the gear shifting process. However, there are others ways to introduce alternative power sources in the vehicle. Simulations are a good way to analyse the dynamic behavior of the vehicle, to generate PMS strategies and to design the real vehicle propelling system and optimizing them for the new driving conditions.

\section{ACKNOWLEDGEMENTS}

This work was conducted during scholarships supported by the Brazilian Federal Agency for Support and Evaluation of Graduate Education (CAPES), National Council for Scientific and Technological Development (CNPq), Pirelli and the State University of Campinas (UNICAMP). 


\section{REFERENCES}

[1] CORRÊA, Fernanda C, ECKERT, Jony J, SILVA, Ludmila CA, SANTICIOLLI, Fabio Mazzarioll, DEDINI, Franco Giuseppe. Application of Fuzzy Logic for Power Management in Hybrid Vehicles. Mecánica Computacional. 2014;XXXIII(number 39 optimization and control).

[2] DELKHOSH, Mojtaba, FOUMANI, Mahmoud Saadat, BOROUSHAKI, Mehrdad. Geometrical optimization of parallel infinitely variable transmission to decrease vehicle fuel consumption. Mechanics Based Design of Structures and Machines. 2014;42(4):483-501.

[3] LI, Qi, CHEN, Weirong, LI, Yankun, LIU, Shukui, HUANG, Jin. Energy management strategy for fuel cell/battery/ultracapacitor hybrid vehicle based on fuzzy logic. International Journal of Electrical Power \& Energy Systems. 2012;43(1):514-25.

[4] RIPACCIOLI, Giulio, BERNARDINI, Daniele, DI CAIRANO, Stefano, BEMPORAD, Alberto, KOLMANOVSKY, IV, editors. A stochastic model predictive control approach for series hybrid electric vehicle power management. American Control Conference (ACC), 2010; 2010: IEEE.

[5] DINÇMEN, Erkin, GÜVENÇ, Bilin Aksun. A control strategy for parallel hybrid electric vehicles based on extremum seeking. Vehicle System Dynamics. 2012;50(2):199-227.

[6] PENNESTRÌ, Ettore, MARITI, Lorenzo, VALENTINI, Pier Paolo, MUCINO, Victor H. Efficiency evaluation of gearboxes for parallel hybrid vehicles: theory and applications. Mechanism and Machine Theory. 2012;49:157-76.

[7] GALLAGHER, Kelly Sims, MUEHLEGGER, Erich. Giving green to get green? Incentives and consumer adoption of hybrid vehicle technology. Journal of Environmental Economics and Management. 2011;61(1):1-15.

[8] LEE, Wah Ching, TSANG, Kim Fung, CHI, Hao Ran, HUNG, Faan Hei, WU, Chung Kit, CHUI, Kwok Tai, et al. A High Fuel Consumption Efficiency Management Scheme for PHEVs Using an Adaptive Genetic Algorithm. Sensors. 2015;15(1):1245-51.

[9] YAZDANI, A., SHAMEKHI, A. H., HOSSEINI, S. M. Modeling, performance simulation and controller design for a hybrid fuel cell electric vehicle. Journal of the Brazilian Society of Mechanical Sciences and Engineering. 2015;37(1):375-96.

[10] EHSANI, Mehrdad, GAO, Yimin, EMADI, Ali. Modern electric, hybrid electric, and fuel cell vehicles: fundamentals, theory, and design. 2009.

[11] SALMASI, Farzad Rajaei. Control strategies for hybrid electric vehicles: Evolution, classification, comparison, and future trends. Vehicular Technology, IEEE Transactions on. 2007;56(5):2393-404.

[12] BAYINDIR, Kamil Çağatay, GÖZÜKÜÇÜK, Mehmet Ali, TEKE, Ahmet. A comprehensive overview of hybrid electric vehicle: Powertrain configurations, powertrain control techniques and electronic control units. Energy Conversion and Management. 2011;52(2):1305-13.

[13] JALIL, Nashat, KHEIR, Naim A, SALMAN, Mutasim, editors. A rule-based energy management strategy for a series hybrid vehicle. American Control Conference, 1997 Proceedings of the 1997; 1997: IEEE.

[14] LIN, Chan-Chiao, PENG, Huei, GRIZZLE, Jessy W, KANG, Jun-Mo. Power management strategy for a parallel hybrid electric truck. Control Systems Technology, IEEE Transactions on. 2003;11(6):839-49.

[15] CIPEK, Mihael, PAVKOVIĆ, Danijel, PETRIĆ, Joško. A control-oriented simulation model of a power-split hybrid electric vehicle. Applied energy. 2013;101:121-33.

[16] CORRÊA, Fernanda Cristina, ECKERT, Jony Javorski, SANTICIOLLI, Fabio Mazzariol, DEDINI, Franco Giuseppi. Implementation of heuristic control techniques in power 
management in hybrid vehicle parallel configuration. Brazilian International Congress of Mechanical Engineering - COBEM 2013.

[17] ECKERT, Jony Javorski , CORRÊA, Fernanda Cristina, SANTICIOLLI, Fabio Mazzariol, COSTA, Eduardo dos Santos, DIONÍSIO, Heron José, DEDINI, Franco Giuseppe. Parallel Hybrid Vehicle Power Management Co-Simulation SAE Technical Paper; 2014.

[18] COSTA, Eduardo Dos Santos, ECKERT, Jony Javorski , SANTICIOLLI, Fabio Mazzariol, DIONÍSIO, Heron José, CORRÊA, Fernanda Cristina, DEDINI, Franco Giuseppe. Computational and Experimental Analysis of Fuel Consumption of a Hybridized Vehicle SAE Technical Paper; 2014.

[19] SILVA, Ludmila CA, ECKERT, Jony J, SANTICIOLLI, Fabio M, COSTA, Eduardo S, DEDINI, Franco G, CORREA, Fernanda C, editors. A study of battery power for a different electric vehicle propulsion system. Electrical Systems for Aircraft, Railway, Ship Propulsion and Road Vehicles (ESARS), 2015 International Conference on; 2015: IEEE.

[20] ABNT, NBR 6601. Light road motor vehicles - Determination of hydrocarbons, carbon monoxide, nitrogen oxides, carbon dioxides and particulate matter in the exhaust gas. October2005.

[21] ECKERT, Jony J, SANTICIOLLI, Fabio M, COSTA, Eduardo S, CORRÊA, Fernanda C, DIONÍSIO, Heron J, DEDINI, Franco G. Vehicle Gear Shifting Co-Simulation to Optimize Performance and Fuel Consumption in the Brazilian Standard Urban Driving Cycle. Blucher Engineering Proceedings. 2014;1(2):615-31.

[22] ECKERT, Jony J, CORRÊA, Fernanda C, SANTICIOLLI, Fabio M, COSTA, Eduardo S, DIONÍSIO, Heron J, DEDINI, Franco G. Gear Shifting Strategies Co-simulations to Optimize Vehicle Performance and Fuel Consumption. Multibody Mechatronic Systems: Springer; 2015. p. 143-52.

[23] GILLESPIE, Thomas D. Fundamentals of Vehicle Dynamics. $1^{\text {st }}$ ed. Engineers SoA, editor. Warrendale, Pa., USA1992 february 1992. 495 p.

[24] MILLIKEN, William F, MILLIKEN, Douglas L. Race car vehicle dynamics: Society of Automotive Engineers Warrendale; 1995.

[25] NAUS, GJL, BEENAKKERS, MA, HUISMAN, RGM, VAN DE MOLENGRAFT, MJG, STEINBUCH, M. Robust control of a clutch system to prevent judder-induced driveline oscillations. Vehicle System Dynamics. 2010;48(11):1379-94.

[26] KULKARNI, Manish, SHIM, Taehyun, ZHANG, Yi. Shift dynamics and control of dualclutch transmissions. Mechanism and Machine Theory. 2007;42(2):168-82.

[27] ECKERT, Jony Javorski , SANTICIOLLI, Fabio Mazzariol, COSTA, Eduardo dos Santos, DIONÍSIO, Heron José, DEDINI, Franco Giuseppe. Influence of the Clutch Model in the Vehicle Longitudinal Dynamics. Brazilian International Congress of Mechanical Engineering - COBEM 2013.

[28] HAIM, Diego. Redução da inércia rotacional no projeto do trem de força. Grad diss, University of São Paulo. 2011.

[29] GAO, Bingzhao, CHEN, Hong, HU, Yunfeng, SANADA, Kazushi. Nonlinear feedforward-feedback control of clutch-to-clutch shift technique. Vehicle System Dynamics. 2011;49(12):1895-911.

[30] YIN, Xiaofeng, XUE, Dianlun, CAI, Yun, editors. Application of time-optimal strategy and fuzzy logic to the engine speed control during the gear-shifting process of AMT. Fuzzy Systems and Knowledge Discovery, 2007 FSKD 2007 Fourth International Conference on; 2007: IEEE.

[31] ZHAO, ZG, CHEN, HJ, ZHEN, ZX, YANG, YY. Optimal torque coordinating control of the launching with twin clutches simultaneously involved for dry dual-clutch transmission. Vehicle System Dynamics. 2014;52(6):776-801. 
[32] KAHLBAU, Sebastian, BESTLE, Dieter. Optimal Shift Control for Automatic Transmission\#. Mechanics Based Design of Structures and Machines. 2013;41(3):259-73.

[33] GM. Owner Manual Chevrolet Celta 2013. General Motors Brazil Ltda; 2013.

[34] XI, Lu, XIANGYANG, Xu, YANFANG, Liu, editors. Simulation of Gear-shift algorithm for automatic transmission based on MATLAB. Software Engineering, 2009 WCSE'09 WRI World Congress on; 2009: IEEE.

[35] SPANOS, PD, CASTILLO, DH, KOUGIOUMTZOGLOU, IA, TAPIA, RA. A nonlinear model for top fuel dragster dynamic performance assessment. Vehicle System Dynamics. 2012;50(2):281-97.

[36] JAZAR, Reza N. Vehicle Dynamics. Theory and Applications Riverdale, NY: Springer Science+ Business Media. 2008.

[37] WALTERMANN, Peter, editor Modelling and control of the longitudinal and lateral dynamics of a series hybrid vehicle. Control Applications, 1996, Proceedings of the 1996 IEEE International Conference on; 1996: IEEE.

[38] JUNZHI, Zhang, YUTONG, Li, CHEN, Lv, YE, Yuan. New regenerative braking control strategy for rear-driven electrified minivans. Energy Conversion and Management. 2014;82:135-45.

[39] LV, Chen, ZHANG, Junzhi, LI, Yutong, YUAN, Ye. Mechanism analysis and evaluation methodology of regenerative braking contribution to energy efficiency improvement of electrified vehicles. Energy Conversion and Management. 2015;92:469-82.

[40] ZHANG, Junzhi, LV, Chen, GOU, Jinfang, KONG, Decong. Cooperative control of regenerative braking and hydraulic braking of an electrified passenger car. Proceedings of the Institution of Mechanical Engineers, Part D: Journal of Automobile Engineering. 2012:0954407012441884.

[41] FUHS, Allen. Hybrid Vehicles: and the Future of Personal Transportation: CRC Press; 2008.

[42] LOPES, M, SERRANO, L, RIBEIRO, I, CASCÃO, P, PIRES, N, RAFAEL, S, et al. Emissions characterization from EURO 5 diesel/biodiesel passenger car operating under the new European driving cycle. Atmospheric Environment. 2014;84:339-48.

[43] AL-HAMMOURI, Ahmad, LIBERATORE, Vincenzo, AL-OMARI, Huthaifa, ALQUDAH, Zakaria, BRANICKY, Michael S, AGRAWAL, Deepak, editors. A co-simulation platform for actuator networks. Proceedings of the 5th international conference on embedded networked sensor systems; 2007: ACM.

[44] BREZINA, Tomas, HADAS, Zdenek, VETISKA, Jan, editors. Using of Co-simulation ADAMS-SIMULINK for development of mechatronic systems. MECHATRONIKA, 2011 14th International Symposium; 2011: IEEE.

[45] HINES, Ken, BORRIELLO, Gaetano, editors. Dynamic communication models in embedded system co-simulation. Proceedings of the 34th annual Design Automation Conference; 1997: ACM.

[46] KIM, Namwook, CHA, Suk Won, PENG, Huei. Optimal equivalent fuel consumption for hybrid electric vehicles. Control Systems Technology, IEEE Transactions on. 2012;20(3):817-25.

[47] MURPHEY, Yi Lu, PARK, Jungme, CHEN, ZhiHang, KUANG, Ming L, MASRUR, M Abul, PHILLIPS, Anthony M. Intelligent hybrid vehicle power control-Part I: Machine learning of optimal vehicle power. Vehicular Technology, IEEE Transactions on. 2012;61(8):3519-30.

[48] ZHANG, Menyang, YANG, Yan, MI, Chunting Chris. Analytical approach for the power management of blended-mode plug-in hybrid electric vehicles. Vehicular Technology, IEEE Transactions on. 2012;61(4):1554-66. 